\title{
PRS Korea 2016 in Its 50th Anniversary
}

\author{
Min Sung Tak ${ }^{1,2}$, Hwan Jun Choi ${ }^{2}$ \\ 'Scientific Programs Committee Chairman of the Korean Society of Plastic and Reconstructive Surgeons; \\ ${ }^{2}$ Department of Plastic and Reconstructive Surgery, Soonchunhyang University Hospital, Soonchunhyang \\ University College of Medicine, Seoul, Korea
}

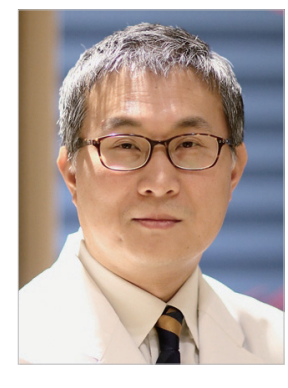

It is our great honor and pleasure to cordially invite and welcome you to PRS Korea 2016, the 74th conference of the Korean Society of Plastic and Reconstructive Surgeons (KSPRS). This year is especially meaningful because the conference is being held in commemoration of the 50th anniversary of the founding of the society [1], and presented jointly with the conference of the Korean Cleft Palate-Craniofacial Association (KCPCA). For this occasion, we have generated diverse, high quality programs, devoted to the advancement of plastic surgery, which are sure to help take us further as a society. PRS Korea 2016 will be held from November 17 to November 20, 2016 at the COEX Convention Center in Seoul. During the past year, the Scientific Programs Committee developed the exciting conference programs, which offer the very latest information on our field. Special events have been organized in celebration of the 50th anniversary of the founding of the society.

PRS Korea 2016 is an international academic conference with participation of plastic surgeons from more than 40 different countries. Founded in 1966 by more than 20 pioneers including Professor Jae-Deok Ryu, the Korean Society of Plastic and Reconstructive Surgeons has grown to become a professional medical society of plastic surgeons with more than 2,000 members and 4,000 associate members. We are pleased that PRS Korea 2016 will be held jointly with the conference of the KCPCA, as the craniofacial sector is considered the foundation of plastic surgery, garnering increased academic interest and developments for clinical applications. KCPCA is preparing to hold its autumn conference in conjunction with KSPRS, which will include in- depth discussion sessions on areas such as craniosynostosis, hemifacial microsomia, cleft lip and palate, head and neck reconstruction, and special topics and keynotes that have not been explored in previous conferences [2].

Highly acclaimed speakers from all over the world will share knowledge on the latest techniques and technologies, ensuring that conference participants have the opportunity to further their professional growth. The success of PRS Korea 2016 will be an opportunity for KSPRS to grow and demonstrate its value as a society of high quality. There will be invited lectures by wellknown speakers who are leaders in their respective plastic and reconstructive surgery disciplines. Symposia will update the audience on recent trends and exchange advanced experience across subfields. We hope there will be active discussions taking place among all the members of the society.

The theme of PRS Korea 2016 is "The 50th Year: The Beginning of a New Era”. The science of plastic surgery in Korea has achieved unparalleled progress with amazing speed over the last 50 years. Unwavering passion for new science and technology, despite great challenges, has led to outstanding advancement in these areas. These achievements will play an integral role in the future of plastic surgery, and in creating a healthy and bright future for all people. The slogan for this conference, "Great strides from the Past 50 Years, Paving the Way for a Beautiful Future," suggests that the advanced science of plastic surgery may provide hope and encouragement for many through the perfect synergy of medicine and aesthetics, treatment and healing, and correction and beauty. 
For this conference we have invited Professor Kiyonori Harii, who will give us a lecture on "Reconstruction for Facial Paralysis." Professor Peter Neligan, one of the authors of the essential textbook Plastic Surgery, will deliver an invited lecture for the special session of the SongBack Lecture, sponsored by the SongBack Foundation. Professor David H. Song, chair of the American Society of Plastic Surgeons, as well as 40 other speakers from 11 countries and societies, will share their views on recent trends and technologies in their own subspecialties. A special event and dinner will be presented to commemorate the 50th anniversary, along with video and a published booklet on its history.

The medical field as a whole faces growing economic challenges year by year, and plastic surgery is no exception. We also have internal challenges in addition to the external ones. As our members face difficulties on their own, conflict with other departments and other medical fields is escalating. Survival in this tough environment, and further advancement of the field of plastic surgery, require your active participation, cooperation, and wisdom. We should equip ourselves with excellent academic and professional skills, which can help us differentiate ourselves from other departments. We can protect our own domain while exploring new techniques and identifying new areas through consistent innovation, and by making new discoveries in existing research areas and applying them to our field. This will help raise the presence of the plastic surgeon and expand our scope of practice.
In commemorating the 50th anniversary of the Korean Society of Plastic and Reconstructive Surgeons, we hope to look back on what we have accomplished as a society so far, and renew our resolution to make further advancements over the next 50 years. The rich programs of this conference are sure to give us such opportunities. The success of PRS Korea 2016 will depend on your participation and support. Your active participation and academic discussions will allow the conference to come to a successful completion. We wish you pleasant and fruitful meetings in PRS Korea 2016. Thank you.

\section{REFERENCES}

1. Kim YB. The history and future of plastic and reconstructive surgery. Arch Plast Surg 2015;42:515-6.

2. Lee Y. Spring update: a letter from the president of the Korean Cleft Palate-Craniofacial Association. Arch Craniofac Surg 2016;17:43.

Correspondence: Min Sung Tak

Department of Plastic and Reconstructive Surgery, Soonchunhyang University Hospital,

Soonchunhyang University College of Medicine, 59 Daesagwan-ro, Yongsan-gu, Seoul 04401, Korea Tel: +82-2-709-9283, Fax: +82-2-796-3543, E-mail: tarkms@naver.com

No potential conflict of interest relevant to this article was reported.

Received: 4 Jul $2016 \bullet$ Revised: 25 Aug 2016• Accepted: 25 Aug 2016 pISSN: 2234-6163・ eISSN: 2234-6171

http://dx.doi.org/10.5999/aps.2016.43.5.393 • Arch Plast Surg 2016;43:393-394 